\title{
LA EDUCACIÓN COLOMBIANA EN LOS INICIOS DE LA INDUSTRIALIZACIÓN DE AMÉRICA LATINA: 1930-1946
}

Muriel Vanegas Beltrán Universidad de Cartagena Colombia 
Panorama Económico, Vol. 27 - No. 1 (Enero - Marzo de 2019), pp. 163-193

Muriel Vanegas Beltrán

JEL: B25, B29

\title{
La educación colombiana en los inicios de la industrialización de América Latina: 1930-1946
}

\section{Resumen}

Este artículo se propone analizar las políticas educativas agenciadas por los gobiernos liberales en Colombia entre 1930 y 1946, articuladas a la coyuntura latinoamericana en la que se propugnaba por la industrialización de sus naciones. Para tal efecto, se discuten las medidas que aspiraban a la renovación del sistema educativo nacional, de cara a dicha tendencia continental, en sus aspectos ideológicos, políticos, económicos y sociales, a fin de identificar algunos de sus principales efectos y resultados en los ámbitos de la educación Normalista, Primaria, Media, Técnica e Industrial. A partir del método de Investigación Histórica y del análisis de Fuentes Primarias soportadas en Informes de Ministros de Educación, de Directores de Instrucción Pública, de Leyes Educativas y Censos de la época, se demuestra que el balance resultante no fue totalmente coherente con los discursos y propósitos que se pregonaban, revelándose así importantes contradicciones con las políticas modernizantes que se introducían, dado el precario respaldo financiero que recibieron por parte del gobierno central en su conjunto.

Palabras clave: Políticas educativas, liberalismo, industrialización, Colombia, América latina.

\section{L'éducation colombienne au début de l'industrialisation de l'Amérique latine: 1930-1946}

\section{Résumé}

Cet article se propose d'analyser les politiques éducatives organisées par les gouvernements libéraux en Colombie entre 1930 et 1946, articulées à la conjoncture latino-américaine dans laquelle il était prôné pour l'industrialisation de ses nations. A cet effet, les mesures qui aspiraient au renouvellement du système éducatif national sont discutées, face à cette tendance continentale, dans ses aspects idéologiques, politiques, économiques et sociaux, afin d'identifier certains de ses principaux effets et résultats dans les domaines de la Enseignement normaliste, primaire, moyen, technique et industriel. À partir de la méthode de recherche historique et de l'analyse des sources primaires soutenues dans les rapports des ministres de l'éducation, des directeurs de l'instruction publique, des lois sur l'éducation et des recensements de l'époque, il est montré que l'équilibre résultant n'était pas totalement compatible avec les discours et les objectifs qui ont été proclamés, révélant ainsi d'importantes contradictions avec les politiques de modernisation qui ont été introduites, étant donné le soutien financier précaire qu'ils ont reçu du gouvernement central dans son ensemble.

Mots clés: Politiques éducatives, libéralisme, industrialisation, Colombie, Amérique latine.

\section{Colombian education at the beginning of the industrialization of Latin America: 1930-1946}

\begin{abstract}
This article intends to analyze the educational policies organized by the liberal governments in Colombia between 1930 and 1946, articulated to the Latin American conjuncture in which it was advocated for the industrialization of its nations. For this purpose, the measures that aspired to the renewal of the national educational system are discussed, facing this continental trend, in its ideological, political, economic and social aspects, in order to identify some of its main effects and results in the areas of Normalistic, Primary, Middle, Technical and Industrial education. From the Historical Research method and the analysis of Primary Sources supported in Reports of Ministers of Education, of Directors of Public Instruction, of Educational Laws and Censuses of the time, it is shown that the resulting balance was not totally consistent with the speeches and purposes that were proclaimed, thus revealing important contradictions with the modernizing policies that were introduced, given the precarious financial support they received from the central government as a whole.
\end{abstract}

Keywords: Educational policies, liberalism, industrialization, Colombia, Latin America. 


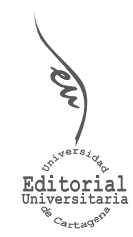

\section{La educación colombiana en los inicios de la industrialización de América Latina: 1930-1946}

INFORMACIÓN DEL ARTíCULO

Recepción del artículo: 27/07/2018

Concepto de evaluación: 01/09/2018

Aceptación del artículo: 18/10/2018
Muriel Vanegas Beltrán*

Universidad de Cartagena, Colombia

\section{INTRODUCCIÓN}

En Colombia, la necesidad de buscar nuevas avenidas para superar las confrontaciones partidistas y las guerras civiles que azotaron la mayor parte del siglo XIX (1812, 1839, 1851, 1854, 1860, 1876, 1884, 1895 y 1899), representaron la urgente tarea de reestructurar la educación nacional para encauzar, a través de ella, la construcción de una nueva nación encaminada hacia el progreso. Así, la entrada al siglo XX estuvo marcada por los resabios de una Hegemonía Conservadora que ostentaba el poder desde 1886, y por la gran crisis económica de 1929, cuyos efectos en la economía nacional se esquivaban desde todos los frentes de la administración pública (Posada, 2015; Bushnell, 2007). En términos económicos, los primeros años del siglo XX trajeron consigo el inicio de un proceso de industrialización que aprovechó la indemnización recibida por Panamá, y los empréstitos extranjeros empezaron a destinarse a la mejora de la infraestructura existente en el país. Las divisas que generaban las exportaciones cafeteras comenzaron a invertirse en la industria, toda vez que la capacidad instalada con la que ésta contaba venía siendo subutilizada (Missaglia, 2015). Para Salomón Kalmanovitz "mientras la mayor parte del mundo se debatía en el estancamiento durante los años treinta, Colombia y otros países latinoamericanos vivieron procesos de intensa industrialización" (Kalmanovitz, 1988, 293). En efecto, la crisis mundial de 1929 obligó al Estado a una paulatina sustitución de importaciones, con lo cual se empezó a robustecer el proceso de industrialización nacional (Palacios, y Safford, 2012).

Este periodo, decisorio para la educación, la política y para la economía nacional, representó una articulación directa con el contexto latinoamericano que enmarcaba al país, toda vez que las asociaciones con los gobiernos como el de Lázaro Cárdenas en México (1934 - 1940), con la Alianza Popular Revolucionaria americana (APRA) de Víctor Raúl Haya de la Torre en Perú y de dirigentes populistas como Albizu Campos en Puerto Rico, permiten establecer los vasos comunicantes de los movimientos de masas de esta coyuntura, signada por la modernización de las instituciones. (Escobar \& Pico, 2015) 
Así mismo, Argentina, reformó la educación con el liderazgo de la provincia de Buenos Aires (Pineau, 1999); en Brasil, la Asociación Brasilera de Educación abanderó la construcción de la "Revolución de 1930" que gestó la Segunda República Brasilera (Chagas de Caravhalo, 1998); en México y Bolivia se promovieron reformas para masificar la educación e integrar al sistema educativo a la población indígena (Schell, 2005; Ossenbach, 2001; Vaughan, 2001; Gonzalbo, 1996); en Chile, el Estado se enfocó en aumentar la cobertura, así como la enseñanza secundaria y vocacional (Ossenbach, 2008, 2001) y en Cuba se impulsó la educación técnica para la industria azucarera. (Ayala y Posada, 2008).

Por tanto, las políticas educativas reformista de los años treinta en Colombia no son la expresión aislada de un sector del Partido Liberal colombiano que lideró tal coyuntura sino, por el contrario, la manifestación nacional de una tendencia continental. Inclusive, ésta "fue una de las versiones más tímidas del proceso latinoamericano" (Urrego, 2005, 16).

El presidente Enrique Olaya Herrera (1930-1934) y sus colaboradores priorizaron la atención a los efectos de la crisis económica y seguidamente se ocupó de emprender reformas sociales y políticas, varias de ellas gestadas en los gobiernos conservadores antecesores, pero siempre postergadas y frustradas por el predominio de fuerzas tradicionalistas y opuestas al cambio, e iniciar así un nuevo periodo en la vida política nacional. De trasfondo, en este panorama subyacía la conciencia generalizada de que la educación era la base fundamental sobre la que descansaba el desarrollo del país y era el ámbito que requería no sólo importantes inversiones y fuerzas de cambio para detener el atraso económico, sino que, igualmente, estuviera en manos de personas letradas (Vanegas, 2018, 217).

Tras la elección de López Pumarejo en 1934, se difunde en Colombia sus iniciativas y discursos "socializantes" que, en buena medida, se sustentaron en la educación. Al ser este presidente liberal partidario de una concepción más social del Estado, se rodeó de un equipo de asesores y ministros progresistas que contribuyeron en la construcción de su programa "Revolución en Marcha", y que extrapolaron en cuatro reformas: Constitucional, Fiscal, Agraria y Educativa. Ésta última normatizó la libertad, de enseñanza así como la obligatoriedad y gratuidad de la educación Primaria (Artículo 14 del Acto Legislativo No 1 del 5 de agosto 1936); en este sentido, se dispuso que la enseñanza debía democratizarse, que las mujeres podían ingresar a todos los niveles de la educación en la misma medida que los hombres, que el Estado se ampararía en la escuela y en la difusión cultural para llegar al campesinado rural y mejorar sus condiciones físicas, materiales e intelectuales. De esta manera, la reforma educativa no solo concernía a niños y jóvenes sino igualmente a la población adulta. A ello buscó responder la campaña de educación rural, las Escuelas Complementarias, Rurales y de Oficios, así como el plan de profesionalización el magisterio. Con esta ruta trazada, el gobierno central asumió la dirección de las escuelas Normales departamentales y abanderó la preparación de los maestros. Se aspiró a la nacionalización, subsidio y extensión de los restaurantes escolares reservados a los niños pobres; se crearon liceos nacionales de enseñanza Secundaria gratuita y se extendió la inspección Primaria a los colegios privados. Por último, López se concentró en reformar la Universidad Nacional y construir una Ciudad Universitaria en Bogotá, como centro receptor y promotor de intercambio de estudiantes a todo el país.

De esta suerte, la renovación del sistema educativo colombiano en la primera mitad del siglo XX no fue un caso particular, exclusivo ni atípico; respondía a las exigencias del rumbo nacional e internacional y se insertó en el marco de los reformismos educativos 
en América Latina, situándose así en una coyuntura continental. En este escenario, los lenguajes políticos se armonizaron con la modernización de los países, como bandera de sus discursos y programas de gobiernos, lo que moldeó las tendencias innovadoras que buscaron democratizar la educación. En este contexto, una incipiente burguesía, un proletariado industrial y agrícola en ascenso, la ampliación de los mercados interiores y la emergente urbanización, forjaron la demanda de una población alfabetizada en los sectores los urbanos y rurales de Colombia, que desembocó en la formulación e implementación de la Reforma Educativa de 1936 (Vanegas, 2018).

Ahora bien, la revisión de las limitaciones y problemas alrededor de los diseños y ejecuciones de las reformas educativas es un eje clave en estos escenarios, al igual que las lecciones derivadas de su implementación. (Vergara et al., 2015). Desde esta perspectiva, diversos autores se han encargado de reflexionar e investigar acerca de las apuestas de transformación de las políticas educativas; sin embargo, la producción bibliográfica, desde los estudios pioneros, hasta los más contemporáneos, revela ciertas desproporciones: Mientras existen aspectos altamente considerados, otros permanecen significativamente ausentes. En términos generales puede afirmarse que son numerosos los trabajos respecto al qué, por qué y para qué de las reformas y transformaciones educativas, pero es escasa la literatura, desde un enfoque histórico, acerca de quiénes y cómo las han llevado a cabo, con qué facilidades contaron y qué dificultades enfrentaron (Silva, 2005; Helg, 2001; Sáenz, Saldarriaga y Opsina, 1997; Jaramillo, 1989; Herrera, 1986; González, 1978; Lebot, 1975; Bohórquez, 1956).

A partir de estas coordenadas temáticas e historiográficas, el presente artículo se propone analizar las políticas educativas agenciadas por los gobiernos liberales en Colombia entre 1930 y 1946, articuladas a la coyuntura latinoamericana en la que se propugnaba por la industrialización de sus naciones. Para tal efecto, se discuten las medidas que aspiraban a la renovación del sistema educativo nacional, de cara a dicha tendencia continental, en sus aspectos ideológicos, políticos, económicos y sociales, a fin de identificar algunos de sus principales efectos y resultados en los ámbitos de la educación Normalista, Primaria, Media, Técnica e Industrial.

\section{EDUCACIÓN NORMALISTA: PROFESIONALIZACIÓN Y DIGNIFICACIÓN DEL MAGISTERIO COLOMBIANO}

Desde 1920, El Director General de Instrucción Pública de Bolívar, Nicomedes Flórez, fue enfático al afirmar que la necesidad de formar un mayor número de maestros es "inaplazable", ya que aquellos que en ese momento egresan de las Escuelas Normales no resultan suficientes para renovar el personal docente de las escuelas primarias. (Flórez, 1921). En opinión de la historiadora Aline Helg "la legislación acerca del nombramiento de maestros no es rigurosa. En principio, sólo las personas con un diploma de escuela normal podían ser nombradas (Helg, 2001, 53). Sin embargo, a la falta de personal titulado, el gobierno autorizaba la vinculación al Magisterio a candidatos que reunieran las siguientes condiciones: "Buena conducta y profesar la Religión Católica. La instrucción suficiente en las materias que deban enseñarse en las escuelas primarias. Conocer la teoría de los métodos pedagógicos de la enseñanza primaria y más especialmente su aplicación práctica" (Decreto No 41 de 1904. Art. 75). Esta norma que venía imperando desde inicios de siglo, poco precisa y que no exigía la profesionalización del maestro para su nombramiento, era la que atendían los gobernadores de los departamentos para designar los maestros urbanos y rurales. Para esta época la mayoría de los departamentos 
se caracterizaban por su elevado número de maestros no graduados. En medio de este panorama, una de las ideas fuertemente impulsadas por la burguesía liberal para atraer el magisterio, comprometerlo en las aspiraciones y tareas de modernización nacional, fue la de emprender campañas que coadyuvaran en hacer de los maestros verdadera mano de obra calificada.

En el año de 1933 se inició la creación de Escuelas Normales Nacionales. Hasta esa fecha, la preparación de los maestros estaba a cargo de los departamentos y se hacía en tan deplorables condiciones y en ausencia completa de elementos de trabajo que se resolvió, entonces, clausurar todas las antiguas escuelas. No obstante, esta compleja situación se hizo extensiva hasta entrados los años treinta, agravada por otras problemáticas:

Si las escuelas hoy existentes no llenan, en su materialidad, las condiciones indispensables para su normal funcionamiento, tampoco los maestros que en ellas enseñan reúnen los requisitos de competencia que su misión reclama. De los 10.000 profesionales de ambos sexos que tienen hoy a su cargo la escuela primaria, sólo un $48 \%$ posee grado de maestro, y aún habría que revisar las fechas de esos títulos y los exámenes y planteles en que fueron adquiridos, pues hay indicios más que suficientes para asegurar que la mayoría de esos graduados pertenece a escuelas y profesa ideas pedagógicas que no tienen valimento ya, ni corresponden en modo alguno a las peculiares necesidades del país en materia de instrucción primaria, ni en muchos casos fueron concedidos con la legalidad que sería deseable, sino antes bien con un criterio de parcialidad política que bastaría a invalidarlos en cuanto se les llamase a una revisión (Ministerio de Educación Nacional, 1936, 31).

Aspiró, entonces, el Ministerio de Educación a entregarle al país 1.000 maestros para fines de 1937, formados en curtos de corta duración denominados cursos de emergencia. "Necesita para ello crear 1.400 becas de \$18 mensuales, para cuya adjudicación se abrirían concursos en todo el país" (Ministerio de Educación Nacional, 1936, 34), admitiéndose en ellos a quienes hayan hecho, como mínimo de estudios, tres años de Bachillerato o de Escuela Normal. En este sentido, se pronunció Darío Echandía en su informe como Ministro de Educación:

El éxito o fracaso de la instrucción normalista dependerá siempre, honorables senadores y representantes, de las mayores o menores facilidades que se le den al estudiante para corroborar o corregir en la práctica de la enseñanza la preparación teórica que viene recibiendo en las aulas. De ahí la existencia en cada Normal de una Escuela Primaria Anexa, en la que el futuro maestro hace sus experiencias metodológicas y pone en ejercicio sus conocimientos. A nosotros no puede interesarnos que una normalista sepa o nó geografía, lo que tiene que preocuparnos es que sepa o nó enseñar geografía. (Ministerio de Educación Nacional, 1936, 67).

Y agregaba que:

...Por la vinculación de la escuela complementaria y de la enseñanza industrial al ritmo de la bolsa de trabajo y al crecimiento económico del país; (por) el mejoramiento en la preparación, recibida por los maestros ambulantes y los inspectores escolares...que entre sí se complementan y que hoy andan distanciadas 
con detrimento de la economía estatal, será necesaria la ampliación y reforma de la escuela normal superior (Ministerio de Educación Nacional, 1936, 69).

Para subsanar y atender estas problemáticas descritas, las Escuelas Normales existentes se reorganizaron y clasificaron en Regulares, que formaban personal docente para las Escuelas Urbanas, y en Rurales, que como indica su nombre, preparaban maestras, principalmente, para servir especialmente en las escuelas de los campos. En 1937 se iniciaron las construcciones de Barranquilla, Pasto, Tunja, Málaga Sincelejo, Mompós y Pamplona. Para el caso del departamento de Bolívar, la Escuela Normal de Mompós tuvo culminado, para dicho año, los tres pabellones de que se compone, con capacidad para 100 alumnas normalistas y 90 niñas de Anexas. La Escuela Normal de Sincelejo tuvo también concluidos sus tres pabellones con la igual capacidad, 100 alumnas normalistas y 90 de Anexa (Ministerio de Educación Nacional, 1936, 34).

Dos años más tarde, en 1939, funcionaban las siguientes Normales Nacionales: siete Regulares para varones, radicadas en Bogotá, Barranquilla, Manizales, Medellín, Pasto Quibdó y Tunja, con un total de 971 alumnos y con 1.457 niños en sus anexas; dos Regulares para señoritas, que son el Instituto Pedagógico de Bogotá y la de Ibagué, con un total de 358 alumnas y con 731 niñas en sus Anexas; y cuatro rurales, establecidas en Bogotá, Gigante (Huila), Popayán y Santa Marta, con un total de 352 alumnas y con 315 niñas en sus Anexas (Ministerio de Educación Nacional, 1939, 36). Funcionaron en el país, además, nueve Normales Regulares Departamentales; ocho de ellas para señoritas, en Bogotá, Barraquilla, Bucaramanga, Cali, Cartagena, Manizales, Medellín y Tunja, con un total de 1.668 alumnas; y una para varones, en Tunja, con 163 educandos. Existían, también, dos Normales Rurales Departamentales, en Manizales y Tunja, y una intendencial, en Istmina (Chocó), con 134 alumnas en conjunto. Por último, hay 8 Normales regulares privadas, 4 en Bogotá, 2 en Pasto, una en Cartagena y una en Cartago (Valle). (Ministerio de Educación Nacional, 1939, 37).

A partir de estos antecedentes, se organizó la Primera Conferencia Nacional del Magisterio, liderada por educadores agrupados en torno a la revista "Educación". Rafael Bernal Jiménez, principal promotor de dicha Conferencia planteó en estos términos el objetivo de la misma:

El programa de los temas que han de ser motivo de discusión y de acuerdo con la Conferencia de 1934, comprende igualmente lo referente a la organización de la Confederación Nacional del Magisterio, organización de carácter permanente que ha de tener por fines principales: el trabajo por el mejoramiento y la dignificación del maestro, tanto por el aspecto de su preparación intelectual como por el de sus condiciones materiales; la vigorización de las federaciones departamentales y la defensa de los intereses constantes de la educación popular (Bernal, 1949, 59-60).

Por tal razón se dispuso que los maestros debían cursar estudios en una Facultad de Educación. De hecho, en materia de profesionalización de educadores, como primer paso para renovar la educación en este contexto, Carlos Low y Martha Herrera argumentan:

Las Facultades de Educación no conocieron larga vida puesto que al fortalecerse en la década del 30 el predominio del Partido Liberal, éste dio un vuelco a su orientación y se propuso constituir sobre sus bases una propuesta en la que prevaleciera la influencia liberal, a la vez que se fundamentó en un modelo pedagógico de corte laico y liberal que tomaba distancia de la pedagogía católica. 
Es así como el Proyecto de la Escuela Normal Superior se abrió paso, dentro del entorno conocido como la República Liberal (Herrera y Low, 1994, 25).

El 12 de febrero de 1934, Manuel J. Huertas, Secretario del Ministerio de Educación Nacional, envío un memorándum al presidente Olaya en el que le solicitaba gestionar una "reorganización en la política educativa del país y una sólida renovación en beneficio del ramo" (Ministerio de Educación Nacional, 1934, 7), en la que se destacan, entre otros, los siguientes planteamientos:

Molesto la atención de Vuestra excelencia con la lectura de la presente carta, que es el resultado de un estudio sereno, adquirido durante el tiempo que he tenido el honor de actuar en la Secretaría del Ministerio, de ver los obstáculos que se oponen para el desarrollo conveniente de las ideas de los Ministros, y del contacto con las personas que se dicen entendidas en asuntos pedagógicos. Obtenida las debidas autorizaciones, sería el caso en entrar a estudiar de manera práctica para obligar a los Municipios a construir los locales para las escuelas urbanas y rurales, y las granjas agrícolas en donde todavía no se ha dado cumplimiento a esta imperiosa necesidad. Se obtendría así la nacionalización de la enseñanza primaria para hacer efectivas las disposiciones que existen sobre la materia (Ministerio de Educación Nacional, 1934,13).

La Ley 12 del 17 de diciembre de 1934 facultó al gobierno para crear el escalafón nacional del magisterio a nivel de Primaria, implementándose con el decreto 1602 del 16 de julio de 1936. El examen de conocimiento, requisito para la clasificación, fue catalogado como "objeto de manejos políticos, en discriminación de los maestros realmente eficaces" (Bohórquez, 1956, 131), lo que obligó a muchos a optar por el sector privado. Posteriormente, El 19 de octubre de 1937, la resolución $N^{\circ} 358$ clasificó la totalidad del magisterio colombiano. Sin duda se trató de un intento por garantizar la estabilidad y ascenso de los maestros, pero no estuvo alejado de los abusos de los inspectores escolares. De hecho, los problemas que se generaron motivaron al Congreso a crear la Ley 97 del 24 de diciembre del mismo año, con la que se cambió el sistema cualitativo de evaluación de la labor del maestro como requisito de clasificación o ascenso. Se introdujo, entonces, la valoración de los diplomas y certificados de estudio, así como los años de servicio para determinar los méritos del ascenso. No obstante, la pretendida estabilidad y promoción del magisterio se quedaron en declaraciones de buenas intenciones. El gamonalismo, proselitismo político y las influencias personales fueron los factores determinantes para el ascenso de los maestros (Duarte, 2003). Éste realmente representó un sistema discriminatorio e injusto que generó el rechazo en el magisterio y en sectores de la opinión pública:

Después de leer la Memoria presentada por el Ministerio de Educación Nacional al Congreso en el presente, queda la sensación de que Colombia avanza a la vanguardia de los países del mundo. Sin embargo, cuán lejos estamos de la realidad. Este ministerio pomposamente llamado de educación, ninguna muestra de preocupación ha dado en favor del maestro de escuela, y decimos en favor, porque la única preocupación del ministerio, ha sido en contra del magisterio: ahí está el famoso escalafón de los maestros efectuado atropellando la justicia: si la pobre maestra no está de acuerdo con el técnico en el motivo por el cual el camaleón cambia de color, queda de inmediato calificada en el último grado. Todo es a conveniencia e interés partidista de quien tiene la sartén por el mango (El Colombiano, 1937, 3). 
En medio de este ambiente cargado de críticas y tensiones, otra de las acciones que se sumaron a las aspiraciones de cualificar el personal docente fue el establecimiento de los cursos de formación de maestros de las Escuelas Anexas a las Normales con el objeto de dotarlos de los conocimientos básicos y fortalecer los que hubieren quedado deficientes en su preparación anterior. Desde su base filosófica, estos cursos no se constituyeron el algo prometedor, dado que su fin primordial era el de llenar las deficiencias y los vacíos que dejaban los inadecuados programas de las Normales, por lo que estos cursos resultaban tan superficiales como los contenidos académicos de aquellas. Aun así, la Sección de Normales creada al interior del Ministerio de Educación en 1938 reglamentó al año siguiente, en 1939, la organización de los exámenes, en tipo y nivel de estudios, las funciones del personal directo y docente, y los procedimientos de carácter administrativo.

Consecuentemente, la creación y expansión de Escuelas Normales registró avances importantes: En 1928 existían en Colombia 28 Escuelas Normales que albergaban 900 alumnos, en precarias condiciones. En 1933 el gobierno las cierra y crea nuevas Escuelas Normales Nacionales, que llegaron a ser 15 en 1942, con 2.200 alumnos (Ministerio de Educación Nacional, 1943). Cuatro años más tarde, Germán Peña, Director de la Sección Normalista del Ministerio de Educación Nacional, haciendo un ejercicio comparativo en el Informe que rinde en 1946, afirma que: "En 1930 estudiaban 202 normalistas por un valor de $\$ 170.857,31$, lo cual da un promedio de costo por alumno de $\$ 845$ anuales. En 1946 se educan 3.515 normalistas con un costo total de $\$ 1.602 .166,22$, lo que da un costo por alumno de $\$ 455$ en el año, a pesar de que el costo de la vida ha subido desde aquella época hasta ahora en proporciones muy grandes" (Ministerio de Educación Nacional, 1946, XVI.

\section{EDUCACIÓN PRIMARIA, ESCUELAS PÚBLICAS Y MATERIALES ESCOLARES: "UNA DE LAS MAYORES PREOCUPACIONES DEL MUNDO PEDAGÓGICO CONTEMPORÁNEO".}

En la costa Caribe colombiana, el departamento del Magdalena, integrado en la temporalidad que abarca este estudio por las áreas que actualmente corresponden al Cesar y buena parte de La Guajira, los pronunciamientos de las autoridades educativas denunciaban continuamente las precariedades imperantes en el panorama educativo en medio de las gestiones reformistas que pretendían modernizar la educación nacional. Para 1930 dichas autoridades declaraban que:

La edificación escolar se encuentra todavía en estado rudimentario. La mayoría de los edificios que ocupan las escuelas son casas construidas sin ningún plan científico, divorciadas de la técnica pedagógica, antihigiénicas, con falta de comodidad y buena ventilación...El local para la escuela reclama una viva atención de los que organizan y dirigen el Ramo, porque de su arreglo depende en parte el normal desarrollo del niño (Informe del Director de Educación Pública al Gobernador del Magdalena, 1930, 10).

Y para el año de 1936, este abandono educativo y las deficientes condiciones se mantenían vigentes, según evidencia la siguiente declaración revelada por el Director de Educación del Magdalena, a Pedro Castro Monsalvo, Gobernador de dicho departamento:

Precisamente era la escuela el lugar menos adecuado para educar e instruir a la niñez. Los locales de propiedad oficial eran contadísimos, aún en los centros 
urbanos de mayor importancia, y para suplirlos se tomaban en arrendamientos inmuebles que no parecían escogidos con criterio pedagógico. Esos recintos eran por lo general lóbregos, estrechos, insalubres y en ellos se hacinaban durante horas interminables a los niños en número mayor muchas veces superior a la capacidad máxima del local (Informe del Director de Educación Pública al Gobernador del Magdalena, 1936, 6).

En el caso de Bolívar (integrado geográfica y políticamente en la época de este análisis por los actuales territorios tanto Sucre como Córdoba y sus respectivos municipios), el entonces Ministro de Educación, Abel Carbonell, exhortó al Director de Educación Pública de dicho departamento a encargarse de la problemática de la educación, en correspondencia oficial fechada 6 de julio de1931, se pronunció en los siguientes términos:

Al iniciar usted las labores del cargo que el Gobierno Nacional ha confiado a sus talentos y patriotismo, sin duda se habrá dado cuenta de la ponderosa y urgente tarea que tiene por delante. Porque aún siendo ello muy doloroso para los amantes de esa gloriosa tierra, hay que reconocerlo: el ramo Instruccionista no ha tenido allí la atención que merece, sino que, al contrario, Bolívar es una de las secciones del país de donde llegan al Ministerio más numerosas y justas quejas por el plano de inferioridad en que se hallan colocados los intereses de la enseñanza popular. Muy bajos los presupuestos departamentales y municipales en los respectivos renglones; sueldos de los maestros, reducidos y pagados con atrasos increíbles; ausencia de estímulos para la organización del Magisterio; locales inadecuados; $y$, en fin, una situación de abandono contra la que es preciso reaccionar enérgicamente y sin demora. Muy grato me será que, bajo la Dirección de usted, se inicie el cambio de frente que exigen los altos intereses y el buen nombre de esa privilegiada región; y para ello, le ofrezco todo el apoyo que al Ministerio sea dable prestarle. (Ministerio de Educación Nacional, 1932, XII).

En 1934, las condiciones locativas de casi todas las Escuelas de Primaria eran descritas en los siguientes términos:

Se encontraban hacinados sesenta o más niños en un local de menos de 50 metros cuadrados de superficie, con bancas bipersonales ocupadas por tres y cuatro, sin luz suficiente...Los locales para las escuelas de Cartagena son en su casi absoluta totalidad inadecuados, estrechos y antiestéticos. Corresponde según legislación vigente, el suministro de ellos a los Consejos Municipales, lo que ya es un gran inconveniente dada la psicología de estas corporaciones (Informe del Director de Educación Pública al señor Gobernador del Departamento. Cartagena, Departamento de Bolívar, 1934, 3).

Todos estos pronunciamientos revelan dos aspectos sustanciales: en primer lugar, que las escuelas se encontraban en precarias condiciones y los locales en los que funcionaban, mal dotados; y en segundo lugar, se pone de relieve la falta de interés de los organismos encargados de atender la dotación de las mismas. Se consideraba que no podría haber una labor constructiva y eficaz en este aspecto de la reforma educacional mientras no se sacara de las manos de los Consejos, para llevarlas a las de un cuerpo Superior Consultivo Departamental, la función primordial del suministro de locales para las escuelas.

Hasta el año de 1936 la nación no tuvo ninguna injerencia sistemática en la provisión de los locales para las escuelas primarias, pues de acuerdo con el Art. $9^{\circ}$ de la Ley 39 de 
1903, se entendía que esta era una obligación que debían satisfacer los municipios con sus propios recursos, aunque con sujeción a planos elaborados por una junta especial. El volumen de las construcciones era notoriamente inferior a las necesidades escolares; sólo los municipios de alguna capacidad económica podían dedicar las sumas indispensables para cumplir con aquella obligación y, cuando ocurría, las escuelas beneficiadas eran solamente las urbanas o parte de ellas, pero las que estaban situadas en el campo nunca o quizá con muy pocas excepciones lograron tener un edificio especialmente construido al efecto.

Además, al analizar los informes de Ministros de Educación y de Directores de Instrucción Pública es notorio que la mayoría de las escuelas así construidas eran deficientes, pese a la Resolución N¹75 de 1904, pues eran generalmente locales de una sola aula, no siempre amplia, en donde debían trabajar las diversas agrupaciones de niños y jóvenes en condiciones antihigiénicas y antipedagógicas. Dada esta situación, el Gobierno Nacional, y particularmente el Ministerio de Educación, comprendió la necesidad de hacer algo por resolver el problema de los locales, en cantidad y calidad, pero ante la imposibilidad de tomarlo exclusivamente de su cuenta, por los grandes recursos que se necesitarían para ello, decidió iniciar una campaña de auxilio a los municipios. En ella se ejerció cierta preferencia a los menos capacitados fiscalmente, y así obtuvo por primera vez que el Congreso de 1936 apropiara en su presupuesto de gastos la suma de $\$ 400.000$ destinada a ser repartida entre los municipios, que a su vez apropiaron determinada cantidad para construir sus locales escolares. Posteriormente se hicieron también apropiaciones nacionales de $\$ 220.000$ y $\$ 250.000$ con el mismo propósito (Ministerio de Educación Nacional, Memoria, 1945, 14).

La campaña encontró dificultades para su desarrollo porque, no obstante haber facilitado a los distritos la constitución de su aporte, permitiéndoles representarlo en las obras escolares que hubieren iniciado o en materiales adecuados al mismo fin, todavía no les era posible cumplir las condiciones básicas señaladas para la distribución de los auxilios nacionales. En total se construyeron 232 escuelas, con una inversión de $\$ 388.379,51$, tomados de las apropiaciones nacionales mencionadas hasta 1940. En dicho año la campaña de los auxilios fue suspendida y se creó en cambio la institución del Fondo de Fomento Municipal, entre cuyas finalidades figura la construcción de escuelas con aportes proporcionales de las tres entidades oficiales: Nación, departamentos y municipios. Por este concepto se construyeron, entre 1940 y 1945, 1.933 locales, por un valor total de \$6.925.868,40 (Ministerio de Educación Nacional, Memoria, 1945, 15).

Las primeras construcciones que se adelantaron beneficiaron en la región Caribe a San Bernardo, San Sebastián (Municipio de Lorica), y Río Nuevo, Garzones y las Babillas del Municipio de Montería. Inmediatamente se procedió a invertir en Cereté, Morroa, Arjona, Sahagún, Ayapel, San Pelayo, Los Cayos (Caimito), San Estanislao. Acto seguido se proyectaron planos para proceder a celebrar los contratos, una vez se tuviera noticias de la cuantía del aporte nacional, de modernos locales del mismo tipo en los Municipios de Ciénaga de Oro, Turbaco, Villanueva, Momil, Mahates, Santa Catalina, Turbana, San Benito, Pinillos, Palomino, san Martín de Loba, entre otros. (Ministerio de Educación Nacional, 1941, 31). 


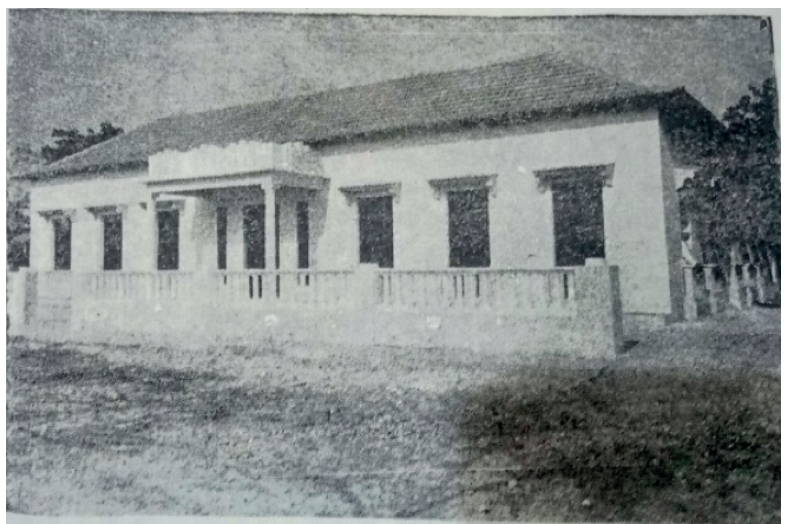

\section{"Moderna Escuela de Arjona"}

Fuente: Galo Alfonso López. (1940). La Educación Pública en Bolívar, 1939-1940. Informe al Gobernador, doctor Manuel F. Obregón. Cartagena: Imprenta Departamental, p. 25.

Afirmó Guillermo Nannetti, Ministro de Educación en 1941,

La escuela primaria en el medio agrícola era una de las mayores preocupaciones del mundo pedagógico contemporáneo. Aunque la reforma pedagógica llegue a satisfacer ampliamente nuestras aspiraciones en lo relacionado con la estructura y contenido intelectual de la escuela primaria, sería incompleta si no afronta otro problema fundamental. La escuela primaria debe preparar para la vida... debe preparar ciudadanos para Colombia. (...) En este punto es fundamental... especialmente lo que se relaciona con la escuela rural, que como es lógico, tiene una función social propia de su medio (Ministerio de Educación Nacional, Memoria, 1941, 24).

Estos planteamientos se correspondían con los estudios e investigaciones adelantados sobre estas problemáticas por la Oficina Internacional de Educación de Ginebra, muy difundidos y aceptados en Colombia durante los años treinta y cuarenta del siglo XX. De hecho, se consideraba universal la tendencia de dar a la escuela en el medio agrícola una orientación agraria eficaz, que permitiese elevar el nivel de vida rural, impedir el éxodo hacia las ciudades, mejorar el rendimiento económico de la región y crear, en fin, un ambiente de atracción y de vocación por los trabajos del campo. Además de Francia, Argentina e Italia, "en Méjico, los programas y métodos de la escuela rural procuran que el trabajo se coordine de tal manera con las actividades del maestro, que el niño, gracias a la educación que recibe, pueda trocarse también en factor de mejoramiento agrícola, industrial y económico del municipio" (Ministerio de Educación Nacional, 1941, 30).

El Ministerio de Educación Nacional era el encargado de proveer y enviar, para todas las escuelas oficiales de la República, materiales escolares. Los Departamentos se encargan de remitirlo a la cabecera de las Zonas Escolares, directamente a los Inspectores Seccionales. Muchas veces el reparto de este material de enseñanza sufría interrupciones porque hay municipios que se niegan a contribuir con el pago de los acarreos hasta las escuelas 
rurales. Ante esta situación se determinó incluir en el presupuesto municipal una partida destinada a atender este servicio. El suministro de material de trabajo en las escuelas fue una de las obligaciones que el Estado procuró asumir con mayor vigilancia y dirección, según las disposiciones que regulaban el fomento de la educación pública nacional.

Desde1930 hasta 1945 se establecen en el presupuesto nacional las siguientes apropiaciones:

Tabla 1.

Presupuestos nacionales para materiales escolares, 1930-1945

\begin{tabular}{|c|c|}
\hline AÑO & $\begin{array}{l}\text { PRESUPUESTO PARA } \\
\text { MATERIALES ESCOLARES }\end{array}$ \\
\hline 1930 & 45.000 \\
\hline 1931 & 45.000 \\
\hline 1932 & 500.000 \\
\hline 1933 & 563.800 \\
\hline 1934 & 250.000 \\
\hline 1935 & 45.000 \\
\hline 1936 & 500.000 \\
\hline 1937 & 463.800 \\
\hline 1938 & 250.000 \\
\hline 1939 & 500.000 \\
\hline 1940 & 290.000 \\
\hline 1941 & 170.000 \\
\hline 1942 & 100.000 \\
\hline 1943 & 100.000 \\
\hline 1944 & 100.000 \\
\hline 1945 & 300.000 \\
\hline
\end{tabular}

Fuente: Ministerio de Educación Nacional, Memoria de 1945. Bogotá: prensas de la Biblioteca Nacional. 1945. p. 6.

Se observa en la tabla anterior que durante los dos primeros años de la República Liberal hubo una apuesta muy baja en la financiación los implementos escolares de todo el territorio nacional, para luego tener una inversión importante en 1932 y 1933. Luego hubo oscilaciones que aumentaban y disminuían abruptamente estos rubros entre 1934 y 1940, presentándose un pico importante en 1936, año de la Reforma Educativa, para seguidamente arrojar una drástica caída de 1941 a 1944, que de inmediato despunta hacia 1945. Tales variaciones de presupuesto se explican no tanto porque el interés del gobierno en la materia hubiera decrecido, sino por las fluctuaciones de las posibilidades fiscales del país, asociadas a los impactos de la Segunda Guerra Mundial en América Latina y por supuesto, en Colombia.

Ahora bien, en relación a la población de estudiantil beneficiaria de todas estas medidas, cabe precisar que por población escolar se entiende el número de individuos de ambos sexos, de edad entre seis y catorce años. Bajo ese criterio, la población escolar se calculó en el 18\% de la población total del año 1934, porcentaje bajo por cuanto corresponde a la 
cifra de 1.506.337 niños de seis a catorce años, tomando la población general en 8.368 .540 habitantes. De dicho porcentaje, solo el 6.22\% de la población total concurre a las escuelas oficiales. (Ministerio de Educación Nacional, 1934, 247).

El porcentaje de analfabetos entre los mayores de diez años es, según el Censo de 1928, del 48.5\%. Entre las regiones cuantitativamente más analfabetas se enumeran, en primer lugar, las Intendencias y Comisarías (a excepción de San Andrés y Providencia), con un promedio del 72\% de analfabetos; en segundo lugar, Boyacá con un 62\%; en tercer lugar Cauca, con un 61,5\%; en el cuarto lugar Bolívar con un 61\% y en el quinto lugar, Huila con un 60\%. Las regiones de menor alfabetismo son San Andrés y Providencia, donde sólo hay un $12 \%$ de analfabetos y el departamento del Atlántico con un $20 \%$. Según estas cifras, los departamentos que registran mayor número de analfabetos son Boyacá, 410.182; Cundinamarca, 369.365; Bolívar, 280.199 y Santander, 260.303. (Censo de 1928).

Ya para 1939, la población nacional era de 9.000.000 de habitantes (Censo de 1938 y proyección del Ministerio de Educación Nacional), con lo que se puede calcular moderadamente en 1.500.000 la cifra de población escolar primaria. Para que toda ella contara con el beneficio de la enseñanza que le corresponde se necesitarían aproximadamente 30.000 escuelas. Ahora bien, según los datos del Ministerio de Educación, en el mencionado año, las Escuelas Primarias oficiales alcanzan a ser 8.595, con un total de 564.257 alumnos, y las privadas llegan a 853, con 38.803 niños. Se tiene, entonces, a 603.060 niños en 9.178 escuelas, lo cual quiere decir que haría falta establecer alrededor de 20.000 escuelas, es decir, elevar el número de las existentes en algo más del $100 \%$.

En efecto, esas 9.178 Escuelas Primarias estaban servidas por 12.156 maestros, por lo tanto, era aún mucho mayor el número de ellos que hacía falta para atender a las 20.000 escuelas que sería preciso abrir para ajustar la cifra de los establecimientos primarios a la de la población escolar respectiva. "Pues bien, sépase que en 1938 se graduaron en 9 de las escuelas Normales nacionales 199 maestros y 110 en 8 Normales departamentales y privadas cuyos títulos acepta el gobierno, o sea un total de 309" (Ministerio de Educación Nacional, 1939, 7), afirma en su memoria el Ministro de Educación Alfonso Araujo.

En materia de construcción y adecuación de los locales escolares, se logró hacer subir de 7.201 escuelas oficiales que funcionaban en 1930 a cerca de 10.460 para 1945 . Paralelamente al aumento de las escuelas, y como es obvio, creció el número de maestros a su servicio; los que trabajaban en 1930 eran 8.708 y en 1945 eran 14.831, sin contar los que prestaban servicio en las escuelas privadas. Pero a pesar de estos importantes aumentos, aún quedaban extensas zonas geográficas y un gran número de personas sin acceso a la educación mínima. (Ministerio de Educación Nacional, 1939, 15).

\section{ESCUELAS COMPLEMENTARIAS Y RURALES: "PREPARACIÓN QUE SIRVA AL FUTURO OBRERO"}

La enseñanza urbana debía tener como prioridad introducir a los hijos de las clases obreras y trabajadoras en el conocimiento técnico de las artes y oficios, de suerte que estas labores manuales no se aprendan, como hoy acontece, simplemente al oído sino también por nota. En un pueblo donde las industrias comienzan apenas a tener un incipiente desarrollo es necesario que a la preparación del personal humano se le dé toda la atención posible. El taller debe ser inseparable de ella. La enseñanza rural debe comprender además del conocimiento de las primeras 
letras, el conocimiento de la tierra. Importa que al campesino no se le desvincule de su medio. Al lado de toda escuela debe funcionar un campo de cultivo, en donde el hijo del campesino vaya conociendo las funciones y propiedades el suelo, del suelo de su región, y vaya adquiriendo conocimientos para más tarde beneficiarse del sembrado en el labrantío de sus padres, no en forma primitiva, como hoy, sino técnicamente. El impulso que esta enseñanza a base de granjas escuelas le dará a la agricultura y por ende a la riqueza nacional, será formidable (Ministerio de Educación Nacional, 1934, XIV).

Bajo estas previsiones, las Escuelas Complementarias empezaron a funcionar especializadas en trabajo manual. Su objetivo y naturaleza era brindar orientaciones que sirvieran para la vida, enfocándose en las necesidades y realidades regionales; de esta suerte, en el caso de la región Caribe, dada su vocación ganadera y agrícola, el gobierno consideró conveniente establecer un internado agrícola auxiliado económicamente por el gobierno nacional, el cual creó por medio del decreto No 31 de 1938, para iniciar con 20 alumnos. Se fundó, igualmente, el Centro de Cultura Social para Obreros y Obreras para los niños que no tuvieron una educación primaria y "menos aún tendrán cabida en la educación secundaria" (Gobernación de Bolívar, 1938, 6). Institutos de esta clase se habían instalado en Bogotá, Tunja y otras capitales. Este centro fue instituido por el decreto No 14 de 1938 para remplazar las Escuelas Nocturnas, que han presentado escasa asistencia. Su objetivo es mejorar la moral y la cultura del pueblo.

Como quiera que el marco imperante en esta coyuntura es el de la modernización e industrialización nacional, el rol fundamental de la educación debía potenciar tal aspiración. Consecuentemente, para lograr la explotación racional del país se hacía necesario especializar y diversificar la formación ofrecida por el sistema escolar. Las prioridades se concentraban en ofrecer a la industria y a la agricultura el personal calificado requerido para ascender hacia el capitalismo, de modo que la educación sería técnica y científica en todos los niveles: "Debemos formar administradores, financistas y diplomáticos, lo mismo que soldados, aviadores y marinos, artesanos y agricultores; obreros calificados y empleados" (Pumarejo, 1934, 115).

Es así como las Escuelas Complementarias fueron creadas por el Ejecutivo Nacional cuando la enseñanza Primaria se reorganizó y se dividió en Primaria y Complementaria, con el fin primordial de impeler los conocimientos obtenidos por los niños durante los cuatro años de instrucción mínima. Para asegurar el cumplimiento de dichos propósitos, entre 1941 y 1942 las Escuelas Vocacionales recibieron un vigoroso impulso. Durante este periodo, se establecieron tres en Nariño, una en el Putumayo, una en Valle, una en Choco, tres en Antioquia, dos en Cundinamarca, tres en Tolima, una en Caldas, cinco en Boyacá, dos en Santander del Norte y se adelantaban estudios para abrir otras en el Cauca, Huila, Bolívar y Magdalena. Finalmente, se logró dar apertura a la Escuela Vocacional Agrícola en el municipio de Turbaco, Bolívar, hacia 1943 y para 1946 existían 35 escuelas de este tipo, distribuidas en todo el país, invirtiéndose la suma de $\$ 847.500$. (Ministerio de Educación Nacional, 1946).

Con estas acciones se aspiraba a contribuir en la solución de un problema social y económico, a la par que técnico, pues tendían a centrarse en la preparación científica a las clases campesinas, garantizando el cuidado de las riquezas naturales y mejorar los productos agrícolas y pecuarios de la región y del país. No obstante la importancia y pertinencia que se declara sobre las Escuelas Complementarias, restricciones presupuestales que las limitaron desde el plano nacional, las afectaron en los niveles 
departamentales. En Bolívar, pese a buscar responder a la vocación agrícola y ganadera de la región y de preparar en la práctica futuros artesanos, no tuvieron los resultados esperados, tal como indican los informes de Directores de Educación Pública de la época:

Las actividades de carpintería, sastrería, zapatería, herrería, plomería, etc., están señaladas para los varones en las Escuelas Complementarias bolivarenses, dando a las mujeres la orientación indispensable para la explotación de las pequeñas industrias caseras y obras manuales en general que les permita una relativa independencia en la vida del hogar. Tales instituciones docentes pueden considerarse como nuevas entre nosotros, sin que haya sido posible darle una seria organización por carencia de recursos, ya que su dotación y sostenimientos exigen ciertas condiciones de local, elementos de trabajo y maquinarias, así como también un profesorado especializado (Ministerio de Educación Nacional, 1934, 27).

Un editorial del periódico El Debate expresa en julio de 1935: "Los niños de los campos concurren a la escuela rural muchas veces milagrosamente, atravesando un camino de largos kilómetros, para ir a sentarse sobre ladrillos" (El Debate, 1935, 1). Este cuadro se agrava con lo que plantea el Director de Educación Pública de Bolívar de 1934:

Muchos de los jóvenes que finalizan sus estudios primarios, no pueden seguir con sus estudios secundarios o hacerse a una profesión en escuelas especiales de Artes y Oficios. En tales escuelas, se ha establecido un pensum apropiado a las circunstancias del medio, de tal manera que en las comarcas agrícolas o ganaderas, se den nociones de agricultura y del conocimiento de la ganadería; y en los grandes centros fabriles se da una preparación que sirva al futuro obrero, tanto en las leyes que lo protegen como en algunas profesiones manuales (Dirección de Educación Pública de Bolívar, 1934, X).

Siguiendo los ejemplos de naciones europeas y de EEUU, el gobierno colombiano, en cabeza del presidente Enrique Olaya Herrera, estableció por el Decreto No 1487 del 13 de septiembre de 1932 las Escuelas Complementarias, restándoles dos años al periodo de enseñanza netamente Primaria. Pese a tales normativas,

...en Bolívar este decreto ha sido mirado con indiferencia y la escuela complementaria no existe, pues aunque hay una en Cartagena, en realidad no se diferencia de las escuelas primarias corrientes ni en el pensum, ni en la organización, ni en el servicio que prestan a la sociedad. Las Escuelas Rurales con son especialmente útiles y urgentes en núcleos de población campesina, justamente donde ha de forjarse el futuro labrador. No obstante, las que vienen funcionando en el departamento no son tampoco lo que, según las disposiciones vigentes, deben ser. En ellas no da la enseñanza dispuesta por la Ley 74 de 1927 y reglamentada por el Decreto Ejecutivo $\mathrm{N}^{\circ} 2.173$ de 24 de diciembre de 1930, y no se imparten las nociones de agricultura dictaminadas para todas las escuelas urbanas, especialmente para las escuelas rurales y para la población campesina (Dirección de Educación Pública de Bolívar, 1934, XII). 


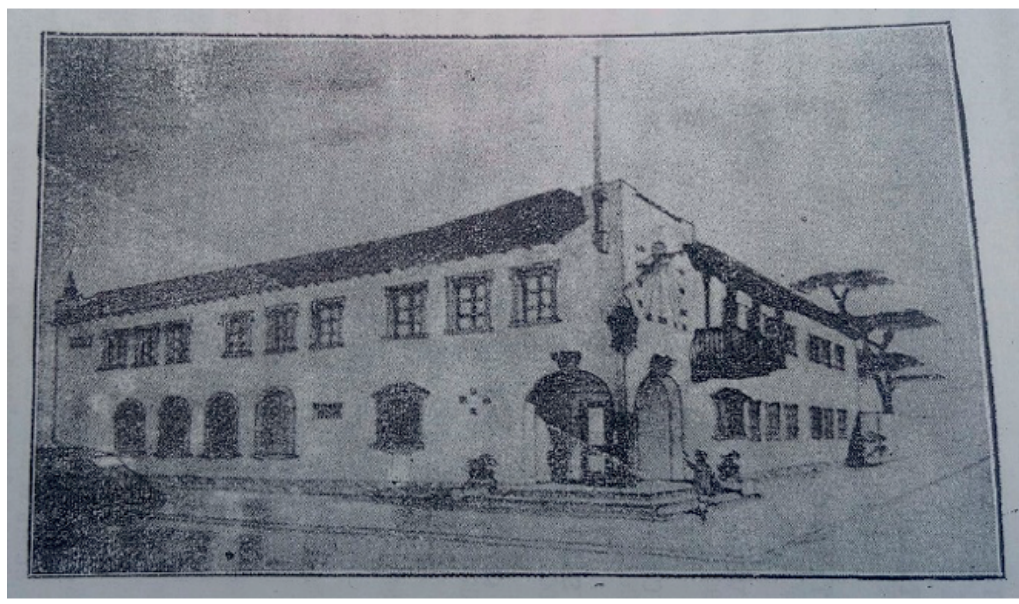

\section{"Croquis de la Escuela Complementaria para varones que funcionó en la Calle Larga, Cartagena, 1942".}

Fuente: Relato del Desarrollo Educativo en el Departamento de Bolívar. (1943). p. 27.

Adicionalmente, son reiterados los pronunciamientos en relación a que "los 4 años primarios son una preparación muy incompleta para los futuros ciudadanos colombianos, por más que se apliquen los programas elaborados por los técnicos del Ministerio de Educación Nacional" (Gobernación de Bolívar, 1938, 15). La mayor parte de las familias de bajos recursos no se encontraban en posibilidades de continuar la educación de sus hijos en colegios de Segunda Enseñanza, fuera porque éstos demandaban gastos considerados excesivos para su reducida capacidad económica o porque requerían del trabajo de sus hijos en las labores del hogar. De ahí que la urgencia por establecer las Escuelas Complementarias, "donde los conocimientos adquiridos se desarrollarán y ampliarán en dos años más de estudios, iniciando a temprana edad en la formación de un arte u oficio, en la mayoría de los casos, determinado mediante vocación o por las circunstancias geográficas y productivas que lo rodean" (Gobernación de Bolívar, 1938, 16). En este punto se destaca el ejemplo de la región del Sinú y Sincelejo, donde los mismos ciudadanos hicieron la oferta al gobierno nacional de establecer una escuela de varones, con miras a la agricultura y la peletería.

\section{COLONIAS ESCOLARES DE VACACIONES: "RECUPERACIÓN FISIOLÓGICA, FOR- MACIÓN INTELECTUAL Y CULTURAL".}

Entre los servicios creados por el gobierno en beneficio de los niños de las escuelas, ocupó un lugar destacado el de las Colonias Escolares de Vacaciones. Una Colonia era un plantel adonde concurrían periódicamente los niños de las escuelas que, por razones de clima o de otra índole, necesitaban atenciones especiales para su recuperación fisiológica, al tiempo que se atendía su formación intelectual y cultural. Se les proporcionaba en ellas, además, alimentación, servicios médicos y de droguería. En Bolívar: 
(...) Acaso por no haberse explicado suficientemente la organización, los fines y los resultados de estas colonias, la partida de $\$ 600.000$ que el ministro de educación anterior reputaba necesaria para este servicio, quedó reducida finalmente a la suma de \$40.000, por lo que este programa iniciará en Valle, Santander del Norte, Boyacá y Tolima, y si acaso en uno o dos años seguiría en Caldas, Antioquia, Magdalena y Atlántico (Ministerio de Educación Nacional, 1936, 17).

Concretamente en la costa Caribe se estableció una Colonia de Vacaciones en la Sierra Nevada de Santa Marta, hacia 1938, a fin de beneficiar las poblaciones de los departamentos Bolívar, Atlántico y Magdalena, a fin de recibir atención médica así como nociones de higiene y de trabajo. En Bolívar, esta medida se acogió y se destinó del presupuesto \$5.000 para tal fin. Llegado el año de 1941 sólo funcionaban once Colonias de Vacaciones Nacionales o apoyadas por la Nación "que buscaban la restauración de los organismos débiles y minados por las endemias de los trópicos" (Atlántico (Ministerio de Educación Nacional, 1941, 38), y se ubicaban en Usaquén (Cundinamarca), Santa Marta, Carmen (Chocó), Arcabuco (Boyacá), Medellín, Bolívar, Santa Bárbara y Carolina (Antioquia) y Pitalito (Huila) y se proyectaba una en Conuco (Cauca).

Para 1945 existían 2 tipos de Colonias que perseguían las mismas finalidades, pero se diferencian en que unas, las nacionales, son íntegramente sostenidas por el gobierno nacional, y las municipales y departamentales, financiadas, con fondos del municipio o del departamento, respectivamente, y auxiliadas por el Ministerio de Educación Nacional. Del primer tipo, en dicho año, existían en funcionamiento nueve Colonias y dos más contaban ya con locales y presupuesto de sostenimiento. Para esas once Colonias existían apropiaciones parciales que sumaban en total $\$ 277.184$. Entre las Colonias auxiliadas por la nación funcionaban 5 en todo el país. El total de estos auxilios era de $\$ 18.800$ (Atlántico (Ministerio de Educación Nacional, 1945, 12).

\section{EDUCACIÓN SECUNDARIA, MEDIA, TÉCNICA E INDUSTRIAL: DE CARA A LA INDUSTRIALIZACIÓN}

En el sector de la Enseñanza Secundaria, el gobierno nacional desplegó un conjunto de acciones casi que inexistentes hasta 1930; encausó sus esfuerzos a través del Ministerio de Educación Nacional para involucrarse directamente a nivel medio al relevar a los departamentos y al sector privado del control de la oferta educativa. De esta manera, en el sector de la Enseñanza Media Secundaria, el Ministerio impulsó el aumento de la oferta educativa nacional a nivel medio. Así, los dos establecimientos oficiales que existían en 1930, llegaron a ser 21 para 1942. Los 19 restantes fueron el resultado de la nacionalización de 10 establecimientos y la creación de nueve (González, 1978, 95).

Por ello mismo, en su mensaje al Congreso del 23 de marzo de 1936, López Pumarejo manifestó que:

La protección a los derechos y las garantías individuales, la libertad de palabra y de prensa, la abolición de la pena de muerte, el desarrollo de la educación pública, no son sino elementales principios del Liberalismo en el Gobierno. El Estado debe garantizar la libertad de enseñanza, reservándose el derecho de vigilarla e inspeccionarla, y la potestad de fijar el grado mínimo de instrucción (López, 1936, 27). 
Estas posturas resultaron en una reorientación educativa expresada en la necesidad de impulsar la educación popular y la alfabetización de sectores urbanos y rurales como condiciones de la industrialización e integración nacional. De ahí el interés por estructurar la enseñanza vocacional con miras a la tecnificación de la educación y la consecuente mejora de la producción agrícola e industrial. Además, con la aprobación de la Ley 257 de 1938 se autorizó al gobierno a celebrar contratos para nacionalizar institutos de enseñanza secundaria, departamentales, municipales o privados.

Desde el punto de vista pedagógico, en este contexto fue clave la modificación de los planes de estudio para el Bachillerato en 1933, 1935, 1936 y 1939: En las primeras innovaciones, el llamado Bachillerato de Cultura General sustituyó el Bachillerato en Humanidades, con una duración de 7 años y especialización en Derecho, Medicina o Ingeniería en lo últimos 3 años. Los 4 primeros años se establecieron como un Bachillerato Elemental y los 7 completos eran el Bachillerato Técnico. Luego, en 1936 se vuelve al Bachillerato clásico de 6 años, y el año $5^{\circ}$ y el $6^{\circ}$ recibieron la denominación de Escuela de Filosofía y Letras. Con relación al número de asignaturas que se impartían a lo largo de este ciclo, de las 24 asignaturas que se daban en 1919, en 1936 se establecieron 86. Este tipo de modificaciones fue criticado por muchos conservadores como Alfonso Uribe Misas, calificándolas como "enciclopedismo y pansofía", resultado del "intervencionismo estatal que se escudaba en la disciplina para imponer la anarquía y el desorden" (Uribe, 1962, 74). La figura de los Inspectores de Secundaria se introdujo en 1938, divididos en peritos en organización escolar, Estudios Sociales, Ciencias Naturales, Matemáticas e Idiomas (Ministerio de Educación Nacional, 1942, 76).

La Resolución No. 59 de 1936 por la cual se dictan algunas normas sobre inspección a los colegios de segunda enseñanza, estableció en su Art. $2^{\circ}$ :

La inspección en referencia dejará a salvo y garantizará la libertad de enseñanza en todo cuanto haga relación a las doctrinas e ideas religiosas, morales, cien tíficas, filosóficas y políticas. Los funcionarios encargados de ejercerla se atendrán estrictamente al precepto anterior y no podrán en consecuencia, criticar, discutir o comentar los principios sostenidos y enseñados al respecto por los profesores de los colegios que inspeccionan los contenidos en los libros de texto y consulta adoptados por los mismos (Ministerio de Educación Nacional, 1959, 128).

Una vez en marcha la Reforma Educativa de 1936, la Educación Secundaria, en general, arrojaba las siguientes características:

Tiene el país en 1936 cerca de 500 establecimientos de enseñanza que se atribuyen el nombre de colegios de bachillerato y que pretenden hacer creer a los padres de familia que se hallan en capacidad de dar a sus educandos los conocimientos necesarios para la adquisición del diploma correspondiente. Sin exageración alguna puede calcularse que a esos 500 establecimientos asiste una población estudiantil no menor de 50.000 jóvenes que forman la masa colombiana que habrá de intervenir en la industria, la agricultura y el comercio privados; en la banca y la administración pública; en los cuadros de mando del ejército y en el clero; en fin de cuentas en la dirección de nuestra vida política, espiritual y económica. (...) De tal manera que bien puedo aventurarme a decir que sin una enseñanza secundaria bien organizada, bien servida y mejor dirigida, no hay universidad posible ni una vida nacional próspera (Ministerio de Educación Nacional, 1936, 72). 
Para remediar este panorama, la Inspección Nacional de Educación Secundaria fue creada en 1938 con el objeto de establecer una vigilancia directa y continua sobre la formación de los futuros bachilleres y para conseguir la unificación de métodos y el mejoramiento técnico de los distintos planteles de Enseñanza Secundaria. Diez Inspectores nacionales tuvieron a su cargo esta tarea y se repartieron en dos comisiones: la una para los departamentos del Magdalena, Atlántico, Bolívar, Caldas, Antioquia, Valle, Cauca, Nariño y las Intendencias del Chocó y de San Andrés y Providencia; la otra para los Departamentos del Norte de Santander, Santander, Boyacá, Cundinamarca, Tolima, Huila y la Intendencia del Meta.

Cada comisión contaba con cinco peritos: el de organización e higiene escolar, el de Ciencias Naturales y Química, el de Matemáticas y Física, el de Estudios Sociales y Filosofía y el de Idiomas y Literatura. Los Inspectores no limitaban su labor a la fiscalización, sino que la extendían a la orientación general de los colegios, a la ayuda y consejo técnico tanto a rectores como a profesores, y a recomendaciones sobre organización, medicina escolar, material didáctico, métodos de enseñanza, iniciativas de trabajo, interpretación de programas y bibliografías de consulta. Se trataba, fundamentalmente, de un programa integral que aspiraba a articular todos los niveles educativos e instancias y autoridades:

Solo el tiempo, la acumulación de ingentes recursos económicos y la estrecha colaboración, no ya sólo de la nación, los departamentos y los municipios, sino de todos los colombianos, hará posible el total cumplimiento de esta reforma instruccionista de la que el país debe esperarlo todo y exigirlo todo (Ministerio de Educación Nacional, 1936, 98).

Una de las medidas tomadas al interior de la enseñanza Secundaria luego de la instauración de la Inspección Nacional y la imposición de programas oficiales, consistió en la fundación en 1936 de los primeros colegios nacionales. Una mirada al contexto nacional revela que esta disposición inició con un Liceo Nacional para jóvenes en Zipaquirá y uno para mujeres en Chía, ambos cerca a Bogotá. Se trató de unos internados que debían funcionar como centros modelos antes de la creación de Colegios Nacionales en todas las capitales departamentales y servir como sitio de prácticas pedagógicas de los estudiantes de la Escuela Normal Superior. Al mostrar poca disciplina, al tener una orientación más social que humanista o científica y una marcada tendencia liberal evidente tanto en la selección de maestros como en el otorgamiento de becas, estos establecimientos pioneros fueron objeto de numerosas críticas. Por tal razón, el último Ministro de Educación del presidente López Pumarejo, Joaquín Castro Martínez, desechó el proyecto de fundar más colegios nacionales, también por limitaciones financieras.

No obstante estos antecedentes, a inicios de 1938, se decidió nacionalizar colegios ya existentes, lo que evitó que el Estado invirtiera en la construcción de nuevos edificios y aprovechara el reconocimiento y prestigio que estos gozaban en las regiones donde funcionaban. El Ministerio se encargaría de su funcionamiento, su organización y su dirección administrativa y pedagógica. En ese año se nacionalizó el Liceo Celedón de Santa Marta, el colegio Pinillos de Mompóx, el colegio de Santa Librada de Neiva y el colegio universitario de Vélez (Santander del sur). Estas instituciones, todas de gran renombre, se ubicaban en ciudades secundarias lo que representaba una ventaja a la hora de extender el campo de acción a regiones poco impactadas por el movimiento de la reforma educativa. 
En la segunda administración de López Pumarejo (1942-1945), se impulsaron importantes modificaciones en el régimen de la segunda enseñanza. En primer lugar, se estableció la inspección de bachillerato encomendada a dos comisiones que permanentemente recorrían el país a fin de comprobar el cumplimiento de los programas oficiales, que los colegios cuenten con el material de enseñanza apropiado y tengan profesores idóneos. Convencido el gobierno de que debería tener un conocimiento completo de la seriedad con que se expedían los diplomas de bachiller, dictó el Decreto No 690 y la Resolución número 514 de 21 de abril de 1942, que fijó el examen oficial de bachillerato en el sexto año con intervención directa del Estado, sobre los programas oficiales y con la colaboración de los colegios públicos y privados.

En general, de 1930 a 1942, la Nación fundó nueve colegios de Segunda Enseñanza y nacionalizó diez. Los colegios fundados fueron: el Colegio Nacional de San Bartolomé, el Liceo Nacional de Varones de Zipaquirá, el Liceo Nacional Femenino de Bogotá, el Externado Nacional de Bachillerato de Bogotá, el Instituto Simón Araujo de Sincelejo, el Colegio Nacional de Chiquinquirá, el Colegio Nacional Emilio Cifuentes de Facatativá, el Colegio Loperena de Valledupar, y el Instituto Nicolás Esguerra de Bogotá. Como se mencionó desde apartados anteriores, los nacionalizados fueron: El Colegio Pinillos de Mompóx, el Liceo Celedón de Santa Marta y el Colegio Universitario de Vélez, a los que se le sumaron el Instituto Universitario del Socorro, el Santa Librada de Neiva, el Instituto Isidro Parra del Líbano, el Instituto General Santander de Honda, el Colegio Académico de Cartago, el José Eusebio Caro de Ocaña y el Colegio Carrasquilla de Quibdó.

De modo particular, la Educación Industrial estaba en la mira de las autoridades desde los inicios de los años treinta. En 1935, el ministro Darío Echandía dirigió sus esfuerzos a crear una escuela industrial en cada capital del departamento, pero su proyecto no se llevó a cabo por falta de recursos fiscales para implementarlo. Fue en la presidencia de Eduardo Santos (1938-1942) que recobró el impulso la Educación Industrial y Artesanal. El entonces Ministro de Educación, Alfonso Araujo, creó la División de la Enseñanza Industrial en el Ministerio de Educación y estructuró una política para financiar a las escuelas existentes, toda vez que los logros que se tenían hasta el momento, eran resultado de establecimientos privados. Las escuelas llegaron a formar obreros especializados y técnicos en electricidad, fundición, mecánica, sastrería, soldadura, ebanistería. Las Escuelas de Artes y Oficios llegaron a ofrecer carreras de tres y de cuatro años, otorgando el título de perito; los Institutos Técnicos Industriales ofrecían un programa de cinco años de estudios con los que otorgaban el título de experto, y por uno de siete años, daban el título de técnico.

En asocio a lo anterior, quizá uno de los mayores logros en el campo educativo en el marco de los gobiernos liberales, se dio a nivel universitario. Desde 1933 Germán Arciniegas propuso un plan de reforma universitaria, que, aunque catalogado por Gerardo Molina como "utópico", le mereció la siguiente afirmación:

Cuando se había iniciado el cambio político que conduciría poco después a la República Liberal, llegó a la Cámara un veterano de las luchas estudiantiles, Germán Arciniegas, quien presentó un Proyecto de Ley Orgánica de la Universidad, cuya larga Exposición de Motivos constituye uno de los mejores trabajos que se han hecho en Colombia sobre la materia (Molina, 1968, 34). 
Arciniegas planteó la necesidad de establecer una reforma que se enfocara sin criterios partidistas, en la que único control en manos del Estado fuese el de proveer los títulos universitarios. En su mensaje al Congreso de 1935, López Pumarejo enunció:

(...) Todas nuestras empresas necesitan un conjunto de trabajadores especializado que no existe en el país. Los promotores, organizadores y directores de ellos carecen generalmente de conocimientos técnicos que no pueden adquirir sino a costa de experiencias fracasadas y ruinosas. Faltan químicos industriales, directores de taller, mecánicos, agrónomos, y no tenemos institutos que estén tratando de prepararlos. Las Facultades universitarias producen abogados, doctores en filosofía y ciencias sociales, médicos, ingenieros y dentistas. Y esto no es suficiente. En esta nueva etapa de la instrucción práctica debe efectuarse casi automáticamente la racionalización de las profesiones artesanas y de ella debe salir el personal técnico que la bolsa del trabajo demande. De tal manera que no sólo suministre al estudiante una profesión, sino que atienda y fomente a la vez la industria nacional" (López, 1935, 28).

Concebida bajo tales lineamientos, la Escuela Industrial sería, a la vez, un establecimiento docente, un regulador en el mercado de trabajo artesano y un centro de fomento e investigación industrial. Dentro de esta nueva organización se establecieron, en 1936, cursos de especialización para oficiales mecánicos, electricistas, fundidores, carpinteros y herreros. Al año siguiente se proyectó el inicio de las especialidades de hojalatería, ebanistería, modelería y construcciones. Ideada en esta forma, la Escuela Industrial de Bogotá debería ser el centro de una vasta organización nacional que cobijara a las escuelas departamentales de artes y oficios y llegase finalmente a controlar y dirigir las Escuelas Complementarias, cuyo profesorado debería formar.

Pero el establecimiento en regla de las Escuelas Industriales en cada una de las capitales de los departamentos, la compra e instalación de sus talleres, el suministro de materias primas, el pago de un profesorado capacitado, eran aspectos que rebasaban considerablemente las partidas presupuestales que los gobiernos seccionales destinan a las Escuelas de Artes y Oficios. "La modernización de ella es cosa que no podría hacerse en cada caso con menos de $\$ 100.000$, dando por supuesto que no hubiese que construir locales. No hay abundancia de razones para presumir que los departamentos puedan o estén dispuestos a imponerse esa erogación" (Ministerio de Educación Nacional, 1946, 50). De $\$ 82.000$ que se gastaban en 1930 en Educación Industrial, se pasó a un gasto de $\$ 1.245 .500$ en 1946. Funcionaban en este último año 82 talleres de trabajo y estudio en las Escuelas Industriales, establecidos en distintas secciones del país por cuenta de la Nación, sin contar con las escuelas de este mismo tipo que han patrocinado los municipios o departamentos como los de Cali, Barranquilla, Bucaramanga y Manizales, consideradas entre las más importantes del país. Igualmente, se organizaron Escuelas Industriales y de Artes y Oficios en Medellín, Pasto, Pereira, Cúcuta, Líbano, Valledupar, Istmina, Chaparal, Chiquinquirá, Neiva, Carmen de Viboral, Carmen de Bolívar y Santa Marta, las cuales graduaron mecánicos, electricistas, fundidores, forjadores, modelistas, ebanistas, carpinteros, mecánicos de motores, radiotécnicos, entre otros.

Jorge Eliecer Gaitán, durante la gestión Ministerial (1940-1941), presentó un informe ante las Cámaras Legislativas, en el que se expresó, frente al panorama educativo nacional, que la población con edad escolar, que va de los 7 a los 14 años, registraba un 57\% de analfabetos, correspondiendo el $80.5 \%$ al sector rural. Su informe le permitió integrar y consolidar sus criterios acerca del problema agrario que relacionó con la educación 
Secundaria, pues consideró que la ineficacia en la preparación de la juventud repercutía en su participación en el mercado laboral:

Hay una amplia zona de ciudadanos que por razón de las actividades que han de desarrollar permanentemente en su medio no encuentran necesario cursar los seis años de bachillerato, pero a quienes les es suficiente para el mismo cometido o propósito la simple instrucción primaria (Ministerio de Educación Nacional, 1940, 37).

En consecuencia, propuso la diversificación del Bachillerato hacia la rama o modalidad Técnica. Durante esta administración tuvo vigencia al plan de estudios que quedó consignado en la reforma promulgada por el Decreto Número 1570 de 1939, el cual acogió principalmente dos principios:

1). Dar en todo momento educación armónica mediante el concurso equilibrado de varias disciplinas. 2). Articular los seis años secundarios en dos etapas definidas y suficientes; una, hasta terminar el año 4o. compuesta de cultura general y práctica, aplicada a la vida en esferas modestas, y a la vez apta para servir de base a estudios posteriores para quien así lo desee; y la otra, el coronamiento superior de los años 5o. y 6o., para completar el bachillerato (Ministerio de Educación Nacional, 1940, 67).

En 1940 había en el país 1.760.083 niños en edad escolar, de los cuales 1.005.037 no asistían a las escuelas. De allí se calcula que, para atender esta población, se necesitarían 20.000 nuevos maestros con formación técnica, sumados a los 13.231 que estaban en ejercicio. Por eso mismo, era indispensable destinar los recursos suficientes para la creación de las escuelas necesarias para formar dichos maestros y articular estos esfuerzos con el incremento en la construcción de planteles educativos: "Es evidente que el país muestra un desarrollo económico e industrial que está en desacuerdo con la preparación Técnica del obrero colombiano. De ahí que, cada vez que surge una nueva industria, sea necesario acudir a técnicos extranjeros" (Ministerio de Educación Nacional, 1940, 90).

En efecto, la senda de la industrialización por la que se encausaba el país más que requerir técnicos, ingenieros o empresarios, exigía obreros, administrativos y mandos medios para todos los niveles del sector productivo y fabril. Las tradicionales escuelas de Artes y Oficios que funcionaban en algunas ciudades del país no estaban en capacidad de proveer esta mano de obra cualificada, por tal razón, desde el gobierno de López Pumarejo de promovió un proyecto de formación de Escuelas Industriales y Comerciales. A la par de ello, para la alfabetizar las masas adultas se adelantaron "campañas de desanalfabetización", implementadas a través de las figuras y modalidades de los maestros ambulantes, las Escuelas Nocturnas para obreros, la radiodifusión, las bibliotecas aldeanas y el cine cultural. En 1936 el Ministerio de Educación contaba con 60 maestros ambulantes, a los que preparó en cursos intensivos en estas ramas consideradas esenciales: Higiene, Economía agraria, Agricultura, Comercio e industrias y en el Dibujo técnico que "por igual beneficia al plomero y al carpintero, al albañil y al herrero, al latonero y al ebanista" (Ministerio de Educación Nacional, 1936, 53).

Sin embargo, no hallándose el Ministerio capacitado económicamente para aceptar la totalidad del costo de instalación y sostenimiento de estas escuelas, procuró estimular su multiplicación mediante auxilios en dinero y material a aquellos departamentos que se comprometieran a suministrar local, profesorado, moblaje, alumbrado, etc., 
y a impartir en ellas los programas oficiales elaborados para este tipo de enseñanza. Sólo los departamentos de Boyacá, Huila, Nariño, Magdalena, Atlántico, Cauca y Santander recurrieron a tales auxilios, logrando la creación de cerca de 30 nuevas escuelas para obreros.

Tomando como base los datos que ofrece el censo de 1938 y circunscribiéndonos a la población mayor de siete años en los departamentos, encontramos que en Colombia había 3.525.814 habitantes que saben leer y escribir por 3.104.920 analfabetos. Es decir, un $46.8 \%$ de la población mayor de siete años para cuya desanalfabetización se requiere de la Escuela Primaria. Esta proporción de alfabetos y analfabetos corresponde por departamentos de la siguiente manera:

Tabla 2.

Proporción de Alfabetos y Analfabetos por Departamentos, 1940

\begin{tabular}{l|c|c|cc}
\hline DEPARTAMENTO & ALFABETOS & $\%$ & ANALFABETOS & $\%$ \\
\hline Bolívar & 222.268 & 37.2 & 375.776 & 62.8 \\
Boyacá & 216.805 & 37.2 & 364.384 & 62.7 \\
Santander & 208.106 & 42.2 & 285.170 & 57.8 \\
Cauca & 11.386 & 42.3 & 160.204 & 57.7 \\
Huila & 76.641 & 44.8 & 94.298 & 55.2 \\
Tolima & 192.814 & 45.4 & 231.479 & 54.6 \\
Norte de & 123.904 & 46.1 & 144.811 & 53.9 \\
Santander & 124.793 & 46.9 & 141.537 & 53.1 \\
Magdalena & 184.152 & 50.3 & 182.201 & 49.7 \\
Nariño & 550.625 & 58.4 & 392.874 & 41.6 \\
Cundinamarca & 134.206 & 62.6 & 80.072 & 37.4 \\
Atlántico & & & & \\
\hline
\end{tabular}

TOTAL

3.525 .814

3.104 .920

Fuente: Ministerio de Educación Nacional, Memoria de 1945. Bogotá: prensas de la Biblioteca Nacional. 1945. p. 6.

Como puede observarse, Bolívar ocupaba el primer lugar de los departamentos con más alto índice de analfabetismo en 1940, junto a Boyacá, con un 62\%, lo que, casi al término de la República Liberal, da cuenta de los pocos alcances y efectos logrados por la reforma educativa en dichos territorios. Tales cifras, por supuesto, generaron alarma y serias preocupaciones en las autoridades y pobladores de los municipios de Bolívar, por lo que tomaron medidas y acciones para disminuir estos indicadores, respaldadas por las autoridades centrales y locales. Adicionalmente, en cada uno de los municipios se constituyó una junta denominada "Junta Municipal", compuesta por el Inspector Local, el cura párroco, el Personero Municipal, además de dos o tres personas de reconocido espíritu cívico, encargados de levantar el censo de analfabetos en la respectiva localidad, tanto en la parte urbana como en la rural, con el fin de propender a la creación de "tantas Escuelas de Desanalfabetización cuantas sean necesarias. Dichas Juntas representan el papel más importante de este movimiento" (Ministerio de Educación Nacional, 1940, 12). 
La multiplicación del libro en las Bibliotecas Aldeanas fue la segunda vía que se siguió para atender la educación popular. En 1936 se lograron 674 bibliotecas que habían repartido unos 95.462 volúmenes sobre la agricultura, la alimentación, la higiene infantil, la vivienda, los animales domésticos, las industrias de la alquería y la huerta, la educación física. A este repertorio se incluyeron en los años siguientes cartillas sobre mecánica, carpintería, peletería, lechería, hojalatería, zapatería "y demás industrias artesanas que entre nosotros se ejercitan empíricamente, al margen de toda la novedad técnica de la época" (Ministerio de Educación Nacional, 1935, 55).

Este mismo empeño por difundir la cultura y la instrucción se vio reflejado cuando, hacia 1941, las Escuelas Ambulantes visitaron 186 municipios de los departamentos de Boyacá, Caldas, Cauca, Cundinamarca, Nariño, Norte de Santander, Tolima, Valle, Atlántico y Bolívar y la Comisaría de Putumayo. También, para ese mismo año se celebraron 16 ferias de libros en Manizales, Bucaramanga, Cúcuta, Ibagué, Armenia, Pereira, Cali, Popayán, Pasto, Neiva, Mompós, Magangué, Medellín, Tunja, Salamina y Anserma. En estas ferias se vendieron en total 386.729 volúmenes por un valor total de \$102.135 (Ministerio de Educación Nacional, 1942, XLVI).

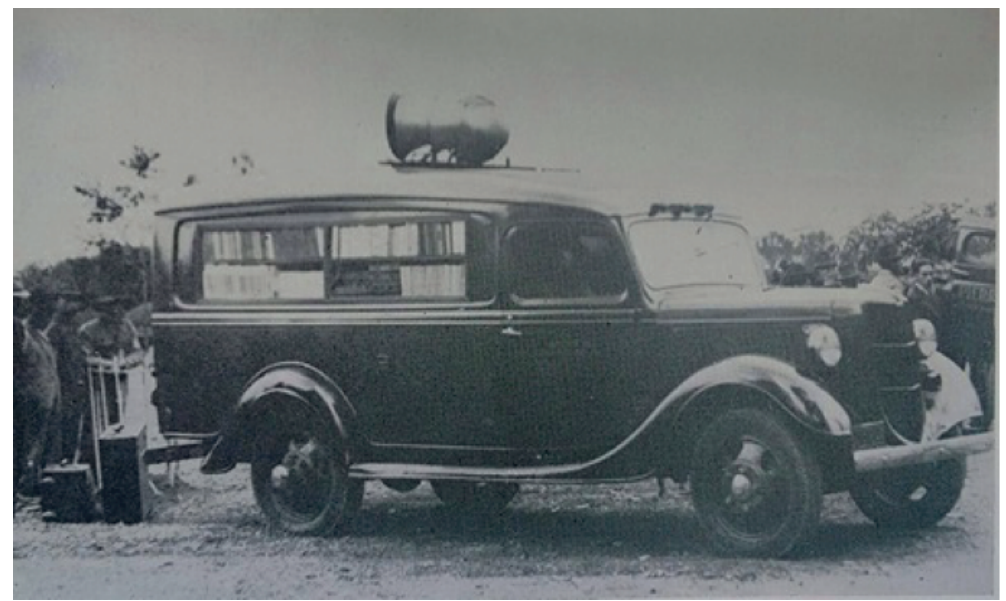

"Primera Sección de las Escuelas Ambulantes. Detalle del servicio de Biblioteca Anexo a cada uno de los equipos de esta Sección".

Fuente: La obra educativa del gobierno. La extensión cultural en Colombia (1940). Tomo III. Ministerio de Educación Nacional. Imprenta Nacional. 


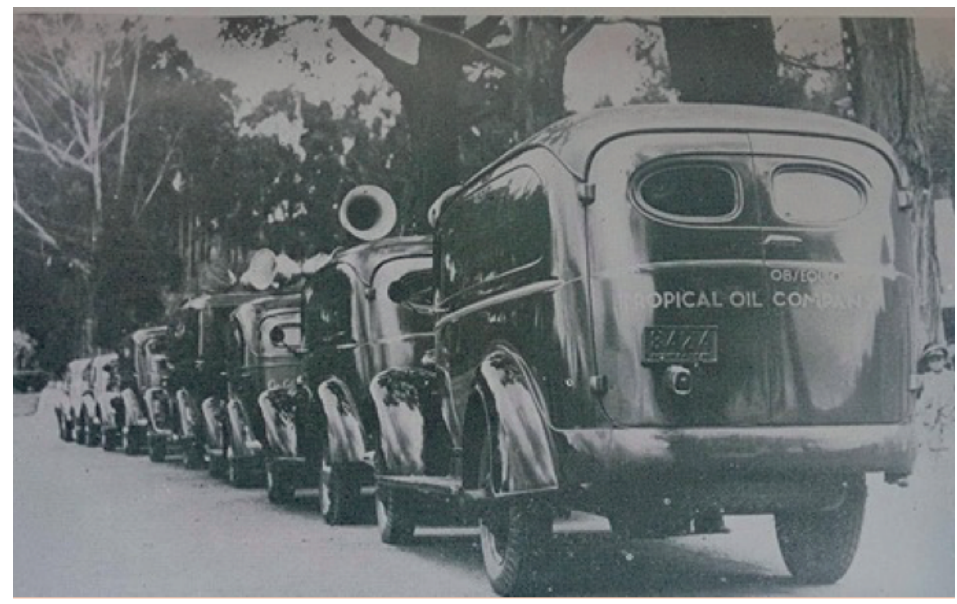

\section{"Otro aspecto de la Primera Sección de las Escuelas Ambulantes, con sus servicios de Biblioteca rotatoria, discoteca y cine educativo".}

Fuente: La obra educativa del gobierno. La extensión cultural en Colombia. (1940).

Tomo III. Ministerio de Educación Nacional. Imprenta Nacional.

Otras de las herramientas educativas y culturales de gran importancia fueron el radio y el cine:

Mediante el primero podrá establecerse entre nosotros una auténtica universidad popular a cuya enseñanza se acoja la totalidad de la población colombiana; por intermedio del segundo, lo que pueda tener de exclusivamente teórico y literario la radiodifusión, quedará corregido por vía gráfica y experimental en la pantalla cinematográfica (Ministerio de Educación Nacional, 1942, XLVI).

Pero las realizaciones efectivas en estos campos, particularmente la "universidad del aire" y la "radioescuela" sólo se empezaron a introducir entrados los años cuarenta. Ciertamente, el Ministerio de Educación aspiraba a multiplicar los cines educativos en todo el país y para ello ofreció dotar a los departamentos de aparatos proyectores y programas completos de películas educativas y culturales en las diferentes poblaciones que suministrasen un local y se ciñeran rigurosamente a los programas elaborados por el Ministerio.

\section{LA LEY ROCHA: "PROCURAR UN AVANCE CONSIDERABLE EN LA EDUCACIÓN DEL PUEBLO COLOMBIANO"}

Una de las medidas más importantes de esta coyuntura fue la Ley 30 de 1944, conocida como la "Ley Rocha", expedida

...con el propósito de procurar un avance considerable en la educación del pueblo colombiano, hasta lograr la eliminación total del analfabetismo. Las cifras de muchachos colombianos en edad escolar que no pueden beneficiarse de la 
instrucción oficial ni particular son tan alta, que por sí sola constituye una de las más serias preocupaciones del Estado (Ministerio de Educación Nacional, 1946, 19).

E1 objetivo primordial de esta Ley fue precisar la forma cómo debían arbitrarse los recursos para una campaña alfabetizadora. Entre sus disposiciones centrales estuvo la creación del Fondo Escolar Nacional, con miras a resolver los problemas de construcción y dotación de locales, la preparación de maestros rurales y urbanos, y el mejoramiento de sueldos para los institutores con el fin de incentivar en la juventud la carrera del magisterio.

La "Ley Rocha" y sus propósitos se cumplieron en forma parcial, tropezando con los reiteradosobstáculos comola falta de presupuesto para realizar obras degran envergadura. Además, ello también implicaba asumir erogaciones que sólo podían materializarse en un país cuyo presupuesto tuviera como función prioritaria la educación. Aun así, en el campo de la Instrucción se introdujeron modificaciones en algunos programas. A las Normales Regulares, por medio de la Resolución No. 1791 de 14 de diciembre de 1945, se les instituyó el plan de estudios que las regiría hasta 1953.

Para finalizar, ciertamente los liberales que ascienden al poder en 1930 realizaron importantes esfuerzos desde el punto de vista pedagógico y financiero para efectuar medidas reformitas en todos los niveles de enseñanza. Al contar con un núcleo de intelectuales con mentalidad moderna que idearon la transformación de las estructuras educativas acordes a la realidad nacional y que preparara a la sociedad para la industria, el trabajo y el ejercicio de la ciudadanía, se dispuso que el primer paso debía darse a nivel constitucional, de la mano del aumento del gasto del Estado destinado a la Educación Pública. Sin embargo, pese a que la ley 12 de 1934 estipuló que el 10\% del presupuesto nacional debía invertirse en educación, las partidas presupuestales ejecutadas oscilaron solamente entre el 7\% y el 8\% (Vanegas, 2018, 273).

El historiador Jaime Jaramillo Uribe sostiene que los recursos destinados al Ministerio de Educación Nacional para atender todas estas iniciativas y políticas educativas reformistas fueron 1.920 .000 en 1934, es decir, el 2.6\% del presupuesto nacional, y en 1938, la suma alcanzó los 7.609.000, a partir de lo cual considera este autor que los recursos destinados a la educación se habían cuadruplicado (Jaramillo, 1989, 93). No obstante, los aportes que dirigían los departamentos a la educación eran superiores a los que aportaba la Nación. Así pues, decantando tales aspectos abordados en este estudio, se arrojan los siguientes hallazgos: En 1935, el MEN aportó, en el caso de la Educación Primaria. 2.532.000, y los departamentos 4.884.000; en 1936, el MEN aportó 5.3111.000, y los departamentos 5.411.000; en 1937, el MEN aportó 6.183.000, y los departamentos 6.387.000. Únicamente entre 1938 y 1939 la tendencia se invirtió: En 1938, la Nación destinó 7.609 .000 (como, en efecto, señaló Jaramillo Uribe), número que se disminuyó a los 6.937 .000 aportados por los departamentos; en 1939, la Nación destinó 7.888.000 y los departamentos 7.671.000. En 1940, nuevamente los departamentos superaron los aportes de la Nación, destinando 7.783.000 frente a 7.467.000 aportados por el MEN.

Como se evidencia, los departamentos fueron los principales soportes económicos de la Educación Primaria, llegando a aportar el 70\% de sus presupuestos educativos en 1940 (8.000.000 de 11.150.000 aproximadamente). La Nación destinaba al presupuesto educativo 8.392.000; los departamentos 11.150.000; los territorios 367.000; y los municipios 3.245.000, y la tendencia se mantuvo así hasta 1946. 
Por ende, más allá de los destacados avances educativos y discursos modernizantes que ampliamente se difundieron en el contexto estudiado, la pervivencia de una visión regionalizada del país, desestatizada y se arraigó en medio de las restricciones que minaron la democratización de la educación de cara a la industrialización nacional. Así, la falta de recursos destinados a los departamentos y municipios por concepto de materiales educativos e inversiones en las construcciones y mejoras de los locales escolares por parte del Estado central, evidencian el abandono y la desidia de unas élites capitalinas que no se despojaron de su investidura oligárquica para crear una nación y una educación moderna e industrializada, a la par del marco latinoamericano.

\section{CONCLUSIONES}

En medio de la tendencia continental de desarrollar un intervencionismo estatal para dinamizar la educación y estimular así las nacientes industrias, el balance de los efectos de las reformas educativas implementadas en Colombia, en el marco de esta coyuntura, arroja un panorama que evidencia que estas fueron concebidas con grandes dificultades y restricciones. Ciertamente, a partir de 1930, las condiciones profesionales del Magisterio empezaron un avance paulatino. Se fortalecieron las Escuelas Normales, se crearon tres Facultades de Educación entre 1932 y 1934 en Tunja y Bogotá, respectivamente. A la vez, se instituyó el Escalafón Nacional para clasificar el ejercicio profesional del maestro según sus estudios y experiencia pedagógica. Pero la mayoría del magisterio de zonas rurales del país aún no contaban con una adecuada preparación en este contexto: en el sector rural, cerca del 90\% de los maestros carecía de formación básica, y en el sector urbano, el 50\% no era egresado de Escuelas Normales ni certificados con grado alguno. En ellos aplicó lo que el Ministerio de Educación Nacional diseñó como aparato regulador de programas, exámenes de revisión, certificación de diplomas, año preparatorio, etc., y lo que en suma representó la creación de la Inspección Nacional de Educación Secundaria en 1938.

Otra acción importante pero de efectos limitados fue la creación del Fondo de Fomento Municipal, en 1938, que buscó impulsar la construcción de escuelas. Aunque se crearon nuevos locales escolares, principalmente entre 1940 y 1945, el incremento de las escuelas fue más bien moderado, pues como se indicó anteriormente, el Estado restringió su aporte presupuestal a dichas construcciones, lo que era esencial no sólo para aumentar el número de escuelas, sino igualmente para mejorar las condiciones locativas de las que ya existían.

Como decantación de las limitaciones planteadas, es hacia 1945 cuando los matriculados empiezan a aumentar en las estadísticas nacionales y regionales; no obstante, para 1947, las tasas de analfabetismos era significativamente altas pues en la mayoría de departamentos superaba el 50\% y $60 \%$, salvo los casos de Atlántico y Cundinamarca, que registraban cifras de $37 \%$ y $41 \%$ respectivamente. En consecuencia, más allá de las acciones de reformas y políticas de innovación implementadas en el periodo en cuestión, las aspiraciones de masificar la educación redundaron en resultados fracasados debido a la pervivencia de condiciones precarias en las estructuras educativas, al insuficiente número de maestros cualificados y las bajas inversiones efectuadas en la enseñanza tecnificada, por lo cual, lejos de poder insertarse Colombia en la coyuntura mundial de la industrialización, el lento progreso registrados en los ámbitos analizados, la situaron en uno de los países con los peores índices en materia educativa desde las primeras décadas del siglo XX. 


\section{REFERENCIAS BIBLIOGRÁFICAS}

Acto Legislativo No 1 del 5 de agosto 1936, reformatorio de la Constitución. Diario Oficial $N^{\circ} 23263$ de 22 de agosto de 1936. Bogotá. Hemeroteca del Senado de la República de Colombia.

Ayala, E. y Posada, E. (2008). Historia General de América Latina. VII: Los proyectos nacionales latinoamericanos: sus instrumentos y articulación, 1870-1930. Madrid: Unesco, Trotta.

Bernal Jiménez, R. (1949). La Educación, he ahí el problema. Bogotá: Ministerio de Educación Nacional.

Bohórquez, L. (1956). La evolución educativa en Colombia. Bogotá: Cultural colombiana, 1956.

Bushnell, D. (2007). Colombia, una nación a pesar de sí misma. De los tiempos precolombinos a nuestros días. Bogotá: Planeta.

Carta dirigida por el Secretario del Ministerio de Educación Nacional al Excelentísimo señor Presidente de la República, sobre reforma educativa y respuesta de este último. (1934). Bogotá: Imprenta Nacional.

Chagas de Caravalho, M. (1998). Molde nacional fôrma cívica: higiene, moral trabalho no projeto da Associação Brasileira de Educação (1924-1931). Bragança Paulista: EDUSF.

Censos Nacionales: 1928, 1938.

Duarte, J. (2003). Educación pública y clientelismo en Colombia. Medellín: Universidad de Antioquia.

El Colombiano. Medellín: noviembre 15 de 1937.

El Debate. Cartagena, 11 de julio de 1935

Escobar-Espinoza, A., \& Angulo-Pico, G. (2015). Panorama Economico in the context of the international visibility of scientific journals. Panorama Económico, 23, 11-13. DOI: https://doi.org/10.32997/2463-0470-vol.23-num.1-2015-1733

Gonzalbo, P. (1996). Educación rural e indígena en Ibeoramérica, México y Madrid: El Colegio de México, UNED.

González, F. (1978). Educación y Estado en la historia de Colombia. Bogotá: CINEP - Serie Controversia, No. 77-78.

Helg. A. (2001). La educación en Colombia: 1918-1957. Bogotá: Serie Educación y Cultura, Universidad Pedagógica Nacional y Plaza \& Janés Eds.

Herrera M. (1986). La Educación en la Segunda República Liberal (1930 - 1946). Apuntes para una historiografía. Revista Colombiana de Educación No. 18.

Herrera M. y Low, C. (1994). Los intelectuales y el despertar cultural del siglo. El caso de la Escuela Normal Superior. Una historia reciente y olvidada. Bogotá: Universidad Pedagógica Nacional.

Informes de Directores Generales de Instrucción Pública al Gobernador del Departamento de Bolívar, 1920 - 1929. 
Informes de Directores Generales de Educación Pública de Bolívar a los Gobernadores del Departamento, 1930-1946.

Informes de Directores Generales de Educación Pública de Magdalena a los Gobernadores del Departamento, 1930-1946.

Informes de Ministros de Educación Nacional, 1920-1946.

Jaramillo, J. La educación durante los gobiernos liberales. 1930 - 1946. En: TIRADO, Álvaro. (ed.). Nueva Historia de Colombia. Tomo IV. Bogotá: Planeta, 1989.

Kalmanovitz, S. [2003] (1988). Economía y Nación. Una breve historia de Colombia. Bogotá: Tercer Mundo Eds. ( $3^{\mathrm{a}}$ ed.).

Lebot, l. (1975). Elementos para la historia de la educación en Colombia. Bogotá: Boletín Mensual de Estadística $\mathrm{N}^{\circ} 249$.

López, A. (1935). Mensaje Presidencial al Congreso de 1935. Bogotá: Imprenta Nacional.

Memorias del Ministerio de Educación Nacional, 1920-1945

Ministerio de Educación Nacional. (1959). División de Normales Superiores y Educación Primaria, Educación Colombiana. Tomo I, Bogotá: Imprenta Nacional.

Missaglia, M. (2015). ¿Se pueden aplicar las ideas Keynesianas al largo plazo? Unas reflexiones teóricas y un modelo ilustrativo. Panorama Económico, 23, 17-30. DOI: https://doi.org/10.32997/2463-0470-vol.23-num.1-2015-1380

Molina, G. (1968). Pasado y presente de la Autonomía Universitaria. Revista Universidad Nacional N¹. Bogotá.

Ossenbach Sauter, G. (2001). "Génesis histórica de los sistemas educativos". En: Organización de Estados Iberoamericanos. Cuadernos de Educación Comparada, 3: Génesis, estructura y tendencias de los sistemas educativos iberoamericanos. Madrid: OEI.

Ossenbach Sauter, G. (2008). "La educación”. En: Ayala E. y Posada, E. Historia General de América Latina. VII: Los proyectos nacionales latinoamericanos: sus instrumentos y articulación, 1870-1930. Madrid: Unesco, Trotta.

Pineau, P. (1999). "Renovación, represión, cooptación. Las estrategias de la Reforma Fresco-Noble (Provincia de Buenos Aires, década del 30)". En: Ascolani, A. (comp.). La educación en Argentina. Estudios de historia. Rosario: Ediciones del Arca.

Palacios, M. y Safford, F. (2012). Historia de Colombia. País fragmentado, sociedad dividida. Bogotá: Universidad de los Andes.

Posada, E. (2015). América Latina en la historia contemporánea. Colombia, Tomo 3: 1880-1930, la apertura al mundo. España: Fundación Mapfre.

Sáenz, J; Saldarriaga, O y Ospina, A. (1997). Mirar la infancia: pedagogía moral y modernidad en Colombia, 1903 - 1946. Bogotá: Colciencias, Ediciones Foro Nacional por Colombia, Ediciones UNIANDES, Editorial Universidad de Antioquia, Colección Clío. 2 Vols. 
Schell, Patience A. (2005). "Entre la libertad y el control. Política educativa mexicana y reacciones desde el Porfiriato hasta la Revolución". En: Di Liscia, M. y Boholavsky, E. (eds.). Instituciones y formas de control social en América Latina, 1840-1940. Una revisión. Buenos Aires: Prometeo.

Silva, R. (2005). República Liberal, intelectuales y cultura popular. Medellín: La Carreta Eds.

Uribe, A. (1962). La libertad de enseñanza en Colombia. Medellín: Bedout.

Urrego, M. (2005). La Revolución en Marcha en Colombia (1934-1938). Una lectura en perspectiva latinoamericana. Morelia: Instituto de Investigaciones Históricas-Universidad de Michoacán de Nicolás de Hidalgo-Revista Nueva Gaceta.

Vanegas, M. (2018). Reformas Educativas y Proyecto de Modernización en Colombia: entre Discursos y Resultados, 1900 - 1950". Saber, Ciencia y Libertad. Publicaciones Universidad Libre. .13, 267 - 282, DOI: 10.18041/2382-3240/saber.2018v13n2.464

Vanegas, M. (2018). La educación pública del departamento de Bolívar durante la primera mitad del siglo XX. Revista Palobra, 18, 216-233. DOI:10.32997/2346-2884-vol.0-num.182018-2172

Vaughan, M. (2001). La política cultural de la revolución: maestros, campesinos y escuelas en México, 1930-1940. México: Fondo de Cultura Económica.

Vergara-De la Ossa, R., Londoño-Vega, C., Pérez-Benítez, N., \& Torres-Castellar, R. (2015). La adopción de las Normas Internacionales de Información Financiera en Colombia. Panorama Económico, 23, 119-132. DOI: https://doi.org/10.32997/2463-0470-vol.23num.1-2015-1382 